\title{
Historia oral y trabajo de campo sobre emigrantes andaluces residentes en Argentina
}

\author{
“GRUPO INTRAKISTORIA": \\ BENITEZ MOTA, Diego; FORERO FERNANDEZ, Montserrat; GOMEZ \\ HERNANDEZ, Pilar, LOPEZ PADIAL, Antonio J.; MACIAS DELGADO, Nieves; \\ MORENO NIETO, Juan; PEREZ MURILLO, Maria Dolores
}

\section{INTRODUCCION METODOLOGICA}

Este trabajo forma parte de un proyecto de investigación, que se viene realizando en la Universidad de Cádiz desde 1992, cuyo título es: Testimonio del flujo migratorio andaluz a América Latina en el presente siglo: Cádiz, plataforma de emigración. Proyecto incluido en el "Plan Andaluz de Investigación" (código 5425).

Nuestra labor consiste en recabar testimonios orales de las personas que, directa o indirectamente, sufrieron la descarnada experiencia de la emigración en este siglo a América Latina. Nuestros informantes, por tanto, se ubican en ambas orillas.

En julio de 1993 dos miembros de los que hoy suscribimos este artículo (María Dolores Pérez Murillo, profesora titular de Historia de América y directora del Grupo de Investigación referido; y Antonio López Padial, arquitecto superiorurbanista, miembro también del grupo) tuvimos la grata experiencia de viajar a la República Argentina y contactar allí con paisanos y parientes, emigrados en el primer lustro de los años cincuenta, y de los que poseíamos "vagas" e "inciertas" referencias. Nada más llegar, pudimos localizarlos sin dificultad, siendo recibidos "con los brazos abiertos". Una informante, totalmente emocionada nos decía:

" "que éste (nuestra presencia) era uno de los acontecimientos más importantes de su vida, pues en más de cuarenta años que faltaba de España, nadie de su familia vino a verla, y ahora estaba dichosa al tenernos con ella".

Curiosamente, aunque nos hallemos en la sofisticada era de las comunicaciones, nunca el hombre se ha encontrado más solo, máxime si vive el exilio de la emigración forzosa, como la antedicha informante, residente en Argentina desde 1952, y huida de la implacable dictadura franquista.

España es un país poquísimo preocupado por sus emigrantes, sobre todo por aquellos que no enviaron divisas o que fracasaron en el sueño o espejismo de "hacer las Américas", hasta el punto de que salir de España, para la inmensa 


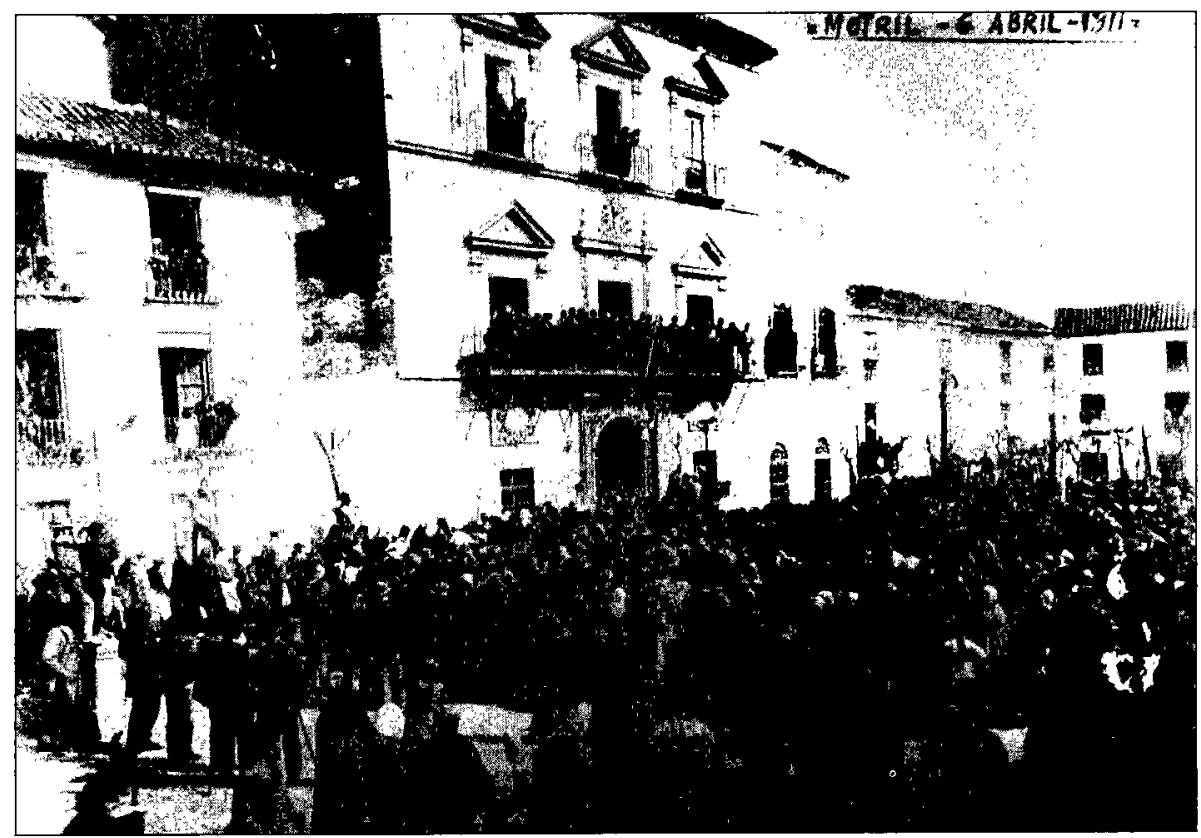

"Manifestación obrera en la plaza de la constitución de Motril el 6 de Abril de 1911, a causa de la depreciación de la caña de azúcar (Archivo Municipal)".

mayoría, era como firmar un acta de defunción, era irse al "nuevo" y "otro" mundo. Esto lo denunciamos al final del presente artículo, al referirnos a las dificultades del "retorno", pues muchos de los que marcharon involuntariamente e impelidos por la dictadura política y económica de la España de la posguerra, ahora en la tercera edad y pobres, no tienen posibilidad de "malvivir" en sus pueblos de origen ya que la pensión no contributiva, a la que tienen "derecho" "todos" los españoles ancianos e indigentes, para ser percibida es necesario llevar dos años de residentes en España; o sea, dos años de "mendigos"...

Retomando el hilo de nuestro trabajo de campo y viaje, desde el primer momento nos integramos plenamente con nuestros informantes, en muchas ocasiones, compartimos su pan y su techo, viviendo plenamente la observación participante que debe existir en toda investigación social y humanistica, que se precie como tal:

-En la ciudad de Buenos Aires hicimos nuestra primera entrevista (de la que más adelante, extractamos, lo más significativo en el epígrafe de "Testimonios"), a un granadino, que en 1952, cuando contaba con cinco años de edad, junto con sus padres forzados a emigrar por la miseria de la posguerra, se vio desvinculado de su tierra de origen. Este testimonio tiene una duración de dos horas, que se complementa con material fotográfico (diapositivas) recabado con una finalidad meramente personal y sentimental, material que no puede ser exhibido, ya que en nuestra investigación mantendremos el anonimato nominal y de imagen de los 
informantes, como es habitual en todo trabajo de campo que sea respetuoso a la intimidad ajena.

El segundo lugar visitado fue la ciudad de Rosario, aquí convivimos durante una semana con las dos personas entrevistadas:

-El primer testimonio proviene de una mujer, soltera y de 68 años de edad, originaria de la ciudad de Motril (Granada) que, en 1952, cuando contaba con 26 años de edad, y como hija de familia, marcha con sus padres y hermano soltero a la República Argentina en busca de un mejoramiento, a todos los niveles, de su propia existencia. Nuestra informante, libre de los prejuicios y de las "mordazas" de la España de la posguerra, nos aporta curiosos datos y analiza con una crítica, en toda regla, no exenta de un hondo sentido del humor, los valores y la situación de la mujer en la sociedad motrileña de los años cuarenta.

-El segundo testimonio, tomado también en la ciudad de Rosario, es el de un varón de 73 años de edad, natural de Motril, de estado civil divorciado (se casa en Argentina con una natural del país) y sin hijos. Su testimonio, dada la erudición personal y minucioso lenguaje, es rico en todo género de detalles, siendo grabados tres "cassettes" de 60 minutos cada uno, con información y temática variopinta: En la primera cinta nos habla pormenorizadamente de su visión personal y erudita de la historia contemporánea (siglos XIX y XX) de la República Argentina: desde la emancipación, pasando por "cuartelazos", populismo, y dictadura hasta la "democracia" néoliberal de Carlos Menen. En la seguncia "cassette" rememora su pueblo de origen, Motril, centrándose en una céntrica calie comercial de esta ciudad, en la que él vivió, denominada "Calle de Catalanes", que haciendo gala a su nombre, es representativa de la burguesía local; en este sentido, nuestro informante nos detalla el origen socio-económico de algunos comerciantes y las "artes" especulativas de los mismos en amasar grandes fortunas durante la primera mitad del presente siglo, siendo este testimonio un minucioso retablo de la burguesía emergente. La tercera cinta grabada es una "historia de vida" sobre su experiencia emigratoria; pero poniéndonos en antecedentes acerca de la tradición migratoria de la costa de Granada hacia América Latina, cuyas causas esenciales radican en el injusto régimen de tenencia de la tierra (minifundios en usufructo), en la crisis del azúcar de caña experimentada a comienzos del siglo XX con el consiguiente movimiento de los obreros del azúcar, manifiesto en la quema de la fábrica del Marqués de Larios, noble absentista y residente en Málaga. Tras estos conatos revolucionarios, la violencia del poder se dejó sentir en las masas obreras y campesinas que, ante la represión oficial, no tuvieron más remedio que exiliarse, poniendo rumbo a las Américas y, concretamente, a las zonas azucareras del Noroeste argentino (Salta, San Miguel de Tucumán, y Santiago del Estero). De todo ello, extractamos lo más significativo en el Testimonio Tercero del presente artículo.

-Adentrándonos en el interior del territorio argentino, y tras pasar por la provincia de Córdoba, llegamos a la ciudad de San Miguel de Tucumán, centro comercial, industrial y cultural del Noroeste argentino. Se trata de una zona azucarera, por antonomasia, de ahí que exista entre su población, un fuerte contingente de las costas de Granada y Málaga pues, a raíz de la crisis cañera andaluza de finales del siglo pasado y comienzos del presente, se produjo un considerable éxodo de obreros y técnicos andaluces hacia la provincia de Tucumán, que sentará sólidas bases de "paisanaje", para atraer nuevas oleadas de inmigrantes andalu- 
ces en los años cincuenta. Hoy, la industria azucarera tucumana presenta un gran declive, que viene experimentándose desde 1966 con el cierre de ingenios por decreto del presidente Onganía. La crisis del azúcar sentó las bases de un fuerte movimiento social, revolucionario, y guerrillero en la zona del Noroeste durante los años sesenta y setenta, cuyo fatal desenlace se produjo con las medidas represivas y de "guerra sucia", iniciadas por López Rega y su "Triple A" (Alianza Argentina Anticomunista), y continuadas por la dictadura militar (1976-1983).

En San Miguel de Tucumán permanecimos diez dias, conviviendo con familias de distinta extracción socio-económica. De nuestro trabajo de campo en la zona, hemos seleccionado una entrevista, que extractamos en el Cuarto Testimonio de este artículo:

-La informante es viuda, tiene 76 años de edad, igualmente es originaria de Motril (Granada), y en 1952 emigra a Argentina con su marido y tres hijos pequeños. El móvil de su marcha es doble: por una parte, la postración económica de la posguerra española y el prometimiento de concesión de tierras que el populismo peronista hizo en aquella época; por otra parte, los vínculos afectivos y de paisanaje que ya existían en la ciudad de San Miguel de Tucumán desde finales del pasado siglo y comienzos del presente.

Para concluir este apartado introductorio y metodológico, insistimos que nuestra técnica investigadora en todo momento ha rehuido la fría entrevista; por el contrario, hemos convivido, compartido y sentido las dificultades de nuestros protagonistas, hemos observado desde la participación, y por ello, la historia que narramos es parcial; pero cierta.

\section{EXTRACTO EXPLICATIVO DE CUATRO TESTIMONIOS ORALES REPRESENTATIVOS}

\section{Primer Testimonio (Buenos Aires, 9 de julio de 1993):}

El informante tiene 47 años de edad, nació en Motril (Granada), a los cinco años emigró con sus padres a Argentina. Vivió en San Miguel de Tucumán hasta los 21 años, edad en la que decidió vivir, independiente de la familia en Buenos Aires. Posee estudios superiores de Economía, trabaja como representante de unos laboratorios farmacéuticos, está casado con una porteña de buen status socio-cultural (psicopedagoga e hija de médico), con la que tiene dos hijos (hembra y varón) adolescentes. Habitan en un barrio de clase media, en una vivienda de $70 \mathrm{mts}$. cuadrados, y en la actualidad tienen algunas dificultades económicas, propias del sacrificio que están sufriendo las clases medias y populares en la Argentina de Carlos Menen, esa Argentina que algunas autoridades de la "macroeconomía" consideran como "milagro económico".

El testimonio oral, la historia de vida que nos narra el informante, posee capital importancia para acercarse al análisis de la institución familiar andaluza, de hondas raices matriarcales y rurales, trasplantada por el proceso migratorio a un nuevo contexto, pero en el que se acentúan los valores tradicionales y de paisanaje endogámico, como últimos recursos de supervivencia a un medio sociocultural desconocido, al que se percibe hostil. Siguiendo el testimonio, vamos a extractar lo más relevante: 


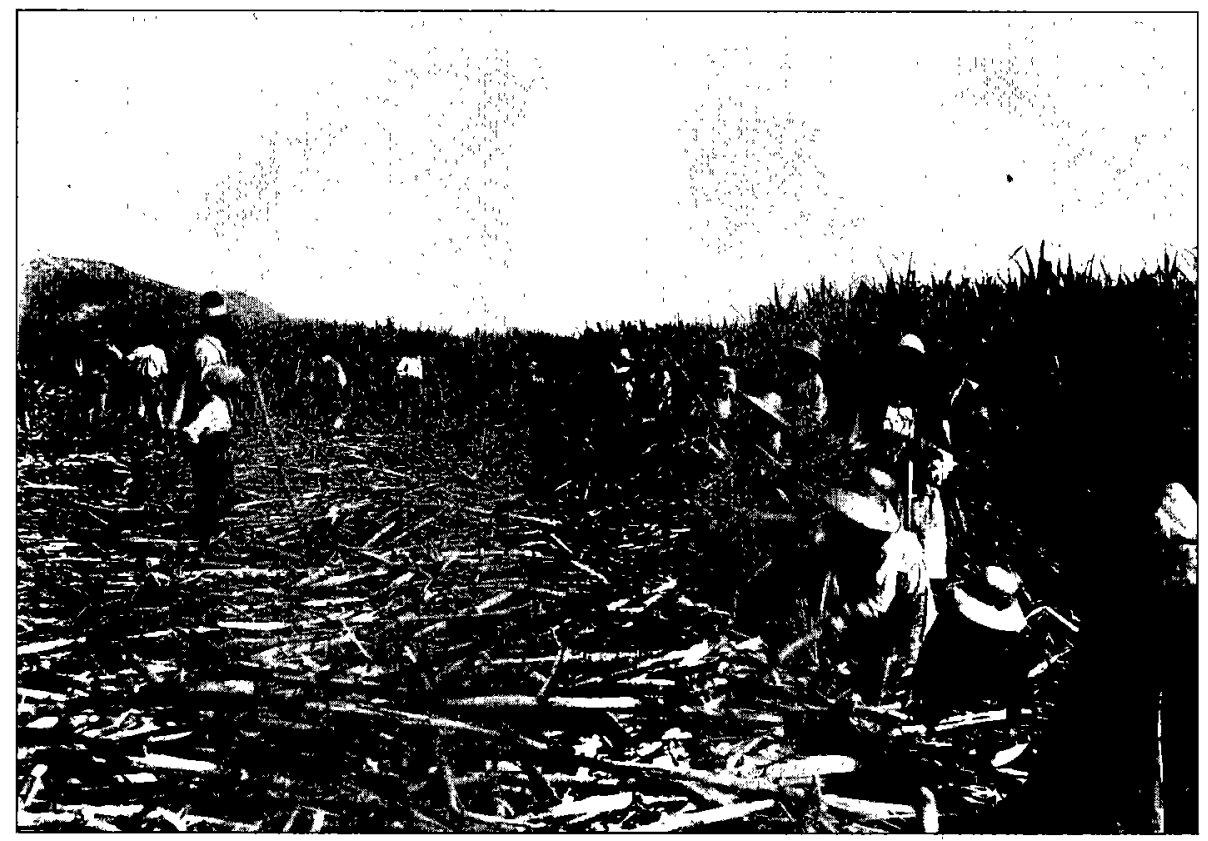

"Escena de la záfra en la vega de Motril, años veinte (Colección Particular)".

\section{-En primer lugar: móviles y trayectoria.}

El móvil de la emigración familiar es de tipo económico: el padre del informante, agricultor de minifundio y originario de las Alpujarras granadinas, con sed y ambición de tierras, quiso creer las promesas populistas de "colonización de la Argentina" preconizadas por Eva Duarte de Perón en su viaje a España en 1947:

"La idea de venir a la Argentina surgió a raíz de la visita de Eva Perón a España, ya que prometió tierras a todo aquel que quisiera ir a la Argentina, porque la idea era colonizar Argentina. Llegamos en enero de 1952; y en julio murió ella (Eva Perón); los papeles que se habían presentado en el banco de la nación quedaron allí archivados o convertidos en papel picado o papel de Diario: Nunca más se supo. Papá quedó parado en la Argentina".

Los costos del viaje y el engaño especulador del que fueron objeto en Cádiz ascendieron a unos 20.000 ptas., ya que en dicha ciudad, la referida familia, formada por el matrimonio y tres hijos hubieron de resistir tres meses en una pensión esperando algún barco mercante, con algo de espacio en sus bodegas, para emprender el viaje sin retorno a la Argentina. Llegaron en enero de 1952 a Buenos Aires, sin dinero; pero un paisano, que viajó con ellos en el barco, les pagó el pasaje de ferrocarril hasta San Miguel de Tucumán, ciudad en la que tenían unos vínculos familiares por línea materna, residentes allí desde finales del siglo pasado. Estos parientes proporcionaron trabajo al cabeza de familia como "alba- 
ñil" en el edificio del diario "La Gaceta"; oficio, no deseado, por el que aspiraba a ser un mediano propietario agrícola:

"El oficio de mi padre era de agricultor, su alma era de agricultor; otra cosa más complicada que la mera agricultura le costaba muchísimo engancharse".

El cabeza de familia, no contento en la ciudad, opta por un contrato de medianería en el medio rural, a $90 \mathrm{kms}$. de Tucumán, a donde se desplaza con su familia. Las vicisitudes de este trabajo y las condiciones de vida, nos son relatadas de esta forma:

"Nos fuimos a un pueblo, llamado San Ignacio, a $90 \mathrm{kms}$. de San Miguel de Tucumán, al sur, a un terreno de un paisano de unas 16 Has., cultivadas la mitad de olivos, y la otra mitad de tomate para conserva y pimiento para pimentón. La larga distancia de la ciudad no nos permitía plantar frutos perecederos. Se trabajaba con un tractor de nafta de 25 c.v.; pero el campo no daba para alimentar a la familia. El patrón nos daba algo de dinero, pero mi padre siempre maldecía porque no nos daba lo suficiente.

La casa en la que vivíamos se hallaba en alto, pues la zona se inundaba. Recuerdo una habitación "grande"..., grande para mi edad (cinco años) sería de cuatro por cuatro, con un techo muy alto, con murciélagos en el techo; mamá nos ponía un pañal sobre la cara para protegernos de las cagadas de los murciélagos. También ésta era una zona plagada de vinchuca. La vinchuca es un insecto que transmite una enfermedad, llamada "mal de Chagas" que, por tratarse de una enfermedad de pobres no se trata farmacológicamente; pues bien, la vinchuca chupa sangre y hace sus deposiciones, en éstas está la bacteria; cuando las deposiciones se secan producen picazón, mientras uno está durmiendo se rasca, y en el rascado se inserta la bacteria que ataca al sistema nervioso y produce malformaciones en el corazón. Ultimamente, leía una estadística en la que se daban 7 u 8 millones de chagásicos declarados; pero como es una enfermedad de pobres, los grandes laboratorios no han hecho desarrollo del tratamiento ni tampoco los laboratorios locales.

Estuvimos año y medio en el campo. Al dueño del terreno le tocó la lotería, se fue a España tres o cuatro meses para "darse la vida padre". El dueño del campo tenía también una tienda de tejidos, pero en estos meses de ausencia, el administrador lo funde todo; así cuando el "dueño" regresa de España se encuentra casi en la ruina y se ve obligado a vender el terreno que ocupábamos nosotros. Tuvimos que regresarnos a San Miguel de Tucumán".

De nuevo en la ciudad, y buscando el apoyo de los parientes, consiguen una humilde casa, hasta que, transcurrido un tiempo y en una zona marginal de la capital pudieron "comprar" un terreno para autoconstruir una "vivienda". Las vicisitudes del "pater familias" y de la familia en general, se nos describen así:

"Papá comenzó a trabajar en una empresa de herramientas agrícolas de importación y de tractores. Trabajó 13 años hasta que la empresa quebró (...). Con la indemnización, papá puso una verdulería que le fue mal... 
Entonces, temporalmente se fue a vivir a Salta y con una camioneta, él y mi cuñado recorrían de 100 a 200 kms., compraban "chivitos" y cerdos a los agricultores, que era gente muy pobre (muy humildes), los traían a Salta, los carneaban y los vendían clandestinamente. Esto duró año y medio, hubo dificultades y papá volvió a Tucumán, allí empezó a gestionar los trámites para cobrar su pensión de jubilación por España".

Hasta aquí hemos referido los móviles migratorios y trayectoria de una familia, siguiendo al "cabeza de familia".

\section{-En segundo lugar: valores, mentalidad y estructura familiar.}

El informante nos describe así a sus padres:

"Mamá no "trabajó" nunca...; bueno tenía cinco hijos; trabajó en el campo sin parientes ni ayuda de tipo alguno. Ella añoró siempre a España, la música española, cuando en la radio había alguna canción española los vecinos llamaban a mamá para que la oyera. Mamá fue sumisa; pero una "mätrona", es decir, con autoridad moral en la familia y' en la vecindad. Mamá siempre pretendió mantenernos unidos.

Papá era agresivo, siempre tuvo la frustración de no haber podido "hacer las Américas". Para él, Argentina era una basura, y lo mejor del mundo era "su" España. Fue violento con sus hijos, pues creía que era el mejor método, ya que así lo educaron a él. Todos sus hijos quisimos escapar de su presión: mis hermanas se casaron a los 18 años, y yo a los 21 me vine a Buenos Aires".

Otros miembros de esta familia, hermanos carnales y políticos del informante, todos residentes en el Noroeste argentino (Tucumán y Salta) son:

- La hermana mayor, de unos 50 años y residente en Tucumán, casada muy joven con un viajante de panadería (cuyo padre era originario de Andalucía y de profesión albañil). Tienen tres hijos; todos casados, sin independencia económica $\mathrm{y}$, por tanto, dependientes de la familia. El sueño del padre, como si de un "patriarca" se tratase, es "agrandar" la casa en la que viven para "recoger" en ella a sus tres hijos, con sus respectivas familias nucleares. Estamos, por tanto, ante el prototipo de una familia patriarcal y extensa que, pese a ser urbana, reproduce valores y comportamientos del medio rural.

-El tercer hermano, de 44 años, residente en Tucumán, vive en un barrio marginal (de viviendas de autoconstrucción sin infraestructura en cuanto a luz y asfaltado de la zona), es como la "oveja negra de la familia". Se casó con una "morocha" (término con una evidente connotación socio-racial marginal) no aceptada, en principio, por el padre. Hoy, esta mujer, de apariencia sumisa, pero de fondo jefa real y efectiva de la familia, es muy valorada en el entorno familiar de su marido, pues desempeña el rol de mujer buena organizadora de la economía familiar deprimida y maltrecha, y es "encarriladora de ovejas descarriadas". Tienen igualmente tres hijos en edades de infancia y adolescencia.

- La cuarta hermana, de 42 años, nacida en Tucumán, residente en Salta, con tres hijos (dos varones y una hembra, ésta casada) se casó a los 18 años con un transportista, vinculado al mundo de los ingenios azucareros salteños. Residen en un barrio marginal de la referida capital. 


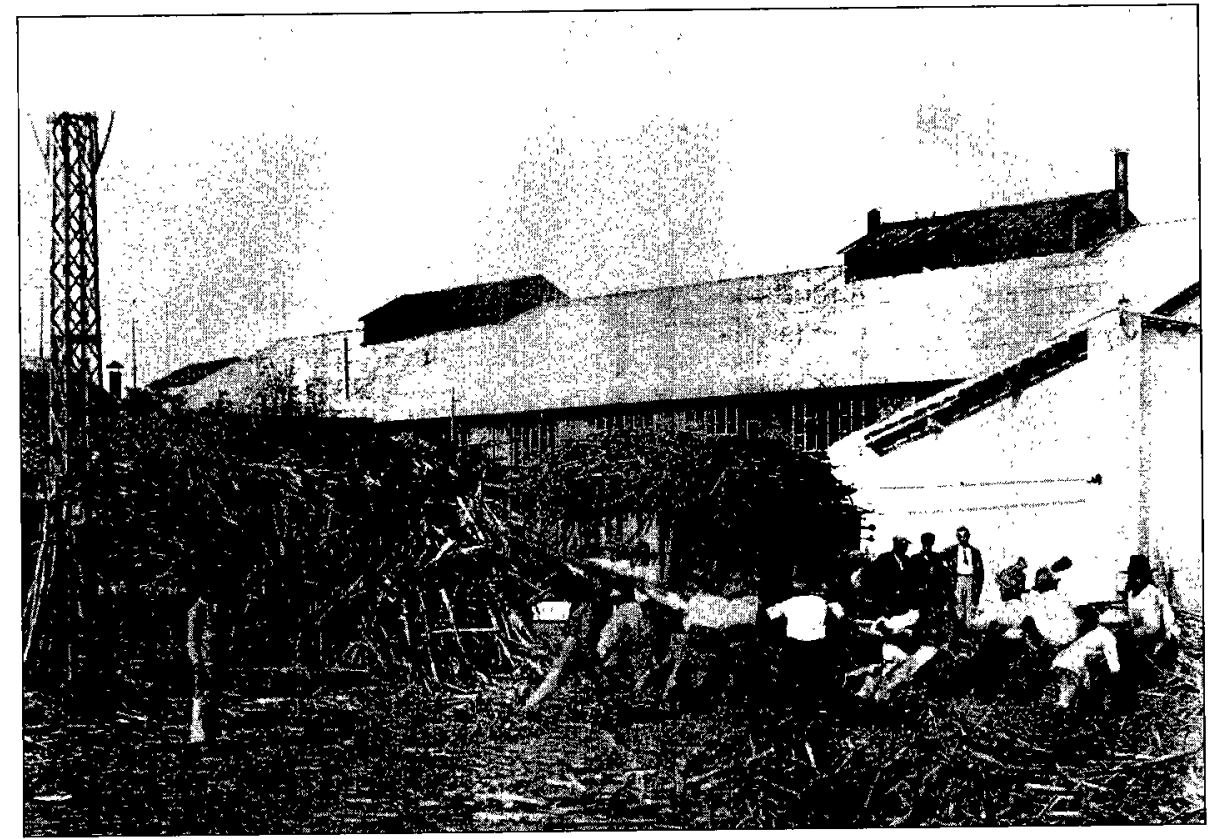

"Descarga de caña en un ingenio azucarero, Fábrica del Pilar (Motril)".

-El quinto hermano, de 38 años de edad y nacido en Tucumán donde reside, se encuentra casado con tres hijos pequeños, vive en la misma casa de su madre, en un barrio "muy pobre", es dependiente de una zapatería, éste es el enlace familiar que mantiene al tanto de cuanto ocurre en el seno de la familia a nuestro informante, residente en Buenos Aires.

De esta familia, quien corrió mejor suerte material es nuestro informante que, ante la crisis económica que se vive en Tucumán en los años sesenta y ante la intransigencia paterna, se ve abocado a trasladarse a Buenos Aires. Brevemente, concluimos este primer testimonio con su trayectoria:

"En 1966, con el presidente Onganía se cerraron 8 ingenios azucareros en Tucumán que generaron 24.000 parados, y pese a los intentos de "reconversión industrial" ya que se crearon tres fábricas (dos de tipo textil y una de armado de televisores) no pudieron éstas absorber a una mínima parte de la población cesante. Todo ello implicó a largo plazo una emigración interior. En 1966, yo llevaba la contabilidad de tres panaderías, ganaba poco, trabajaba mucho y tenía dificultades para ingresar en la Facultad. En 1968, me fui a Buenos Aires. Los primeros meses fueron muy difíciles, pues no conocía a nadie, a nada, ni los mecanismos que se generan en una gran ciudad (de 12 millones de habitantes). Llegué pesando $84 \mathrm{kgs}$., y en cuatro meses adelgacé 20 kgs. El problema básico era de cómo vivir, dónde vivir. Empecé a trabajar llevando contabilidades. Me alojaba en una pensión, en donde compartía 
una habitación con cinco personas más. Tuve variados trabajos de contabilidad, que alterné con estudios superiores de Económicas. Me compré un departamento y me casé".

\section{Segundo Testimonio (13 de julio de 1993)}

Nuestro informante es una mujer soltera de 68 años, nacida en Motril (Granada). A la de edad de 26 años marcha junto al resto de su familia (padre y un hermano) hacia Argentina a la búsqueda de una deseada prosperidad. En la actualidad reside en la ciudad de Rosario (Argentina) junto a su hermano de 73 años de edad, en la actualidad divorciado. Ambos sobreviven gracias a la exigua pensión que reciben del Estado (apenas 15.000 pts. cada uno).

El presente testimonio, aunque parco en ciertas cuestiones, nos ofrece la posibilidad de conocer la experiencia de una mujer que sufrió junto al resto de su familia la experiencia de la emigración. Su narración arranca de las vivencias juveniles en Motril de los años cuarenta, y avanzando a través del tiempo expone diversos aspectos de gran interés: situación familiar, trabajo femenino, infraestructura del viaje, valores y mentalidad, etc. La entrevistada narra amable y cordialmente los hechos y apenas se muestra reticente a las preguntas que siempre contesta. A veces es asistida en sus respuestas por su hermano también presente.

Al ser diversas las cuestiones que se tratan, sus contestaciones, poseen matices que van desde el sarcasmo a la aflicción pasando por la añoranza. En cambio no demuestra excesivo resentimiento hacia la dureza de los acontecimientos, pero tampoco resignación. Su carácter optimista y positivo, tantas veces demostrado imprimiendo valor y energía a su familia durante los malos momentos, le llevan a restar dramatismo a los acontecimientos.

La familia poseía con anterioridad a la partida hacia Argentina una buena posición socio-económica. El padre regentaba en Motril un pequeño comercio que les permitía vivir desahogadamente y sin necesidades. La narración de este periodo de su vida nos permite conocer aspectos interesantes de la estructura familiar, situación social de la mujer, así como valores.

Hasta la llegada a Argentina la vida de nuestra informante transcurre según las pautas características de una joven de clase media. Su condición de mujer le comprometía a formar en un futuro un nuevo núcleo familiar, por lo que desde muy joven fue instruida en las labores del hogar. A pesar de ello, su educación y la de su hermano no fue severa, y en ella se atisban ciertos aires de liberalidad (mayores en el caso del hermano) excepcionales para la conservadora moral de la época:

“... a nosotros no nos limitaron para nada. Tuvimos plena libertad para hacer lo que queríamos, dentro de lo normal. Mi hermano se descarriaba un poco, pero (ríe)... yo era más obediente. Por eso mi hermano me dice ahora, que yo antes era muy buena, ahora no...".

De enorme interés resulta la visión de la religiosidad femenina en el Motril de los años cuarenta. La entrevistada narra con humor e ironía las periódicas visitas de misioneros a su pueblo, con el objeto de adoctrinar a sus habitantes. Las enseñanzas de estos misioneros iban especialmente dirigidas a las mujeres casa- 
das, y en ellas se hacía un especial hincapié en el fomento de la natalidad, muy en consonancia con la política de desarrollo demográfico propugnada por el régimen franquista. Los misioneros actuaban en los locales pertenecientes a la oligarquía motrileña nacida del estraperlo, o en cualquiera de las parroquias del pueblo donde celebraban misas, realizaban coloquios, confesiones, etc.:

"Todas las que eran casadas salian rojas cuando iban a confesarse con los misioneros, porque los misioneros les decían que había que traer... tener a todos los hijos que Dios dé, fue así. Y entonces, la que decía que no podía, porque no los podía mantener, y quería tener a su familia en condiciones, que no les faltara nada, no les daba la absolución, así de simple. Después se confesaban casi todas, pero yo no vi después que Motril creciera..., así que todo era falso".

Al igual que el resto de las mujeres, la entrevistada, aunque soltera, asistía a estos actos religiosos en los que se hacía defensa de los valores tradicionales, y que a su vez eran aprovechados para hacer proselitismo de las ideas reaccionarias del régimen. En la actualidad, y como consecuencia de un enjuiciamiento de los valores aprendidos en su juventud, para lo cual ha tenido una vital importancia la experiencia americana, posee una visión bastante crítica de aquellos sucesos:

“... porque ahora que yo me siento en plena libertad comprendo lo que fue eso, una falsedad, sociedad hipócrita. Eso es lo que entiendo lo que fue el Motril de ese tiempo...".

Con enorme sarcasmo expone:

"... no sé exactamente los días que estuvieron con pláticas, todos los días, y misas, y rosarios de la aurora, y todas esas cosas, confesiones, para dejar las almas en paz, bien tranquilas".

Ya hemos comentado con anterioridad que el motivo que induce a la emigración a esta familia se encuentra en el deseo de obtener una mayor prosperidad. Pero en esta acción juega un papel fundamental el hermano de la informante, deseoso de hacer fortuna en América. Su decisión arrastrará al resto de la familia. La unión existente entre los miembros de la familia, ejemplo claro de matriarcado en el que la madre posee un fuerte carácter sustentador, compartido, y tras su muerte heredado por su hija, resultó esencial en la determinación final. La entrevistada narra como la posible pérdida de su hijo estimula a sus padres en última instancia a seguir sus pasos:

“... porque mi hermano quería venir a América, y quería venir a América, y empezamos: ¡Ay, si se va el niño lo vamos a perder, si se va lo perdemos! y estabamos una noche sentados en la mesa de camilla en el gabinete y se... y dijo papá: ¿y si nos fuéramos todos?. Bueno, y ahí nos vamos y nos vamos".

En 1952, fecha en la que la entrevistada junto al resto de su familia se dirige hacia Argentina, se produce un aumento considerable en el número de emigran- 


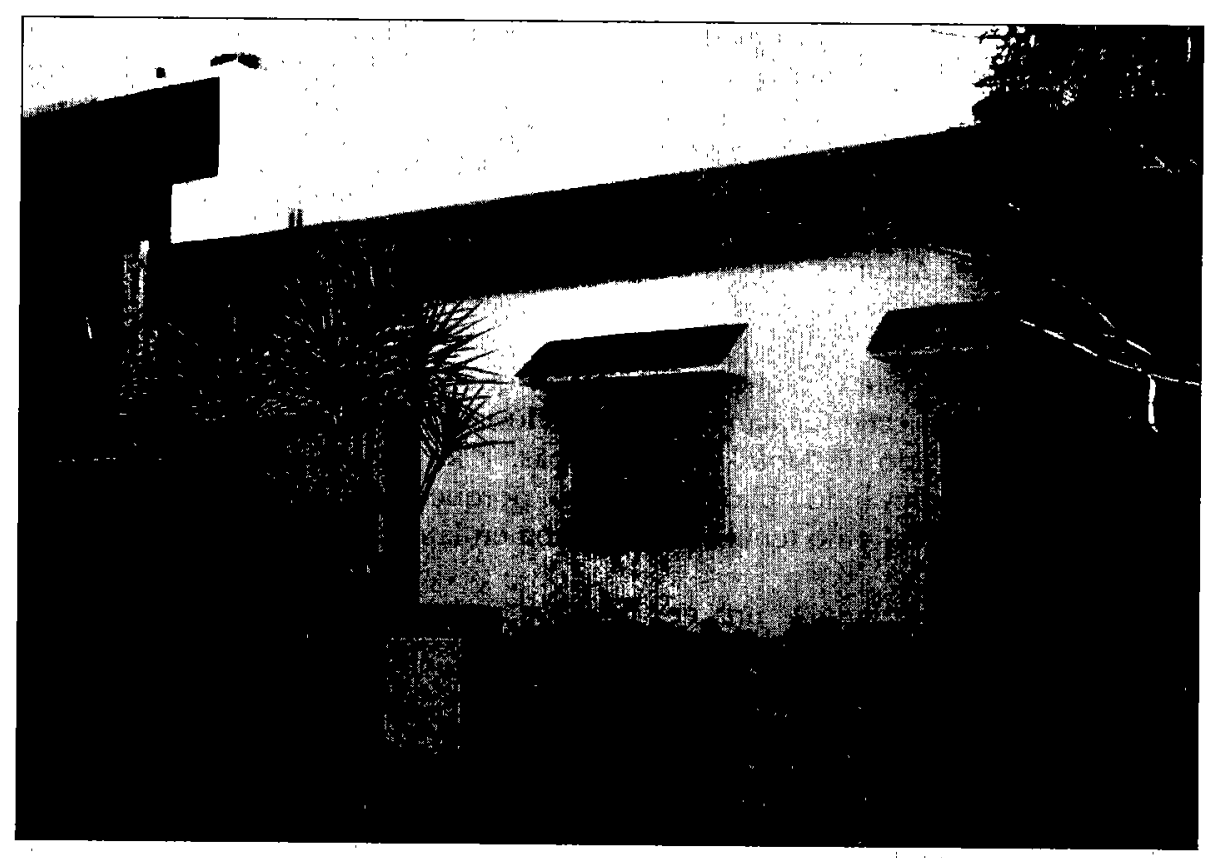

"Tipo de vivienda de unos emigrantes andaluces residentes en Rosario (Republica Argentina)".

tes españoles que viajan hacia América Latina como consecuencia de la apertura de la política internacional del régimen franquista. Pero aún persistían importantes trabas para la libre circulación de emigrantes, impuestas tanto por el gobierno español, cuya política de fomento de la natalidad, se contradice con la salida indiscriminada de jóvenes del país (las autoridades españolas imponen como requisito el que los emigrantes para poder viajar aportaran una carta de llamada o contrato de trabajo), como por parte de los países latinoamericanos receptores que persistían en sus políticas restrictivas.

Las dificultades para salir del país, provocaron la aparición de una mafia dedicada a la emigración ilegal que actuaba en la ciudad de Cádiz, cuyo puerto era uno de los más empleados en esta fecha para los viajes a ultramar. Numerosos emigrantes fueron víctimas de su especulación, entre ellos la familia de nuestra entrevistada. Poseían una perfecta organización, sus redes se extendían por la mayoría de los pueblos andaluces, adonde eran enviados sus "ganchos" con el objeto de reclutar emigrantes. Fue precisamente uno de estos "ganchos", un tal Don Francisco, propietario de un hotel en Cádiz, quien tras una visita a Motril, consigue como clientes a la familia de nuestra entrevistada. A dicho personaje pagan los pasajes (17.000 pts. por persona) que recibirán a la llegada a Cádiz. Hasta que no son alojados en el barco, el "Cabo de Hornos", no son conscientes que han sido engañados, ya que habían sido obligados a comprar billetes de primera clase y no de tercera más cercanos a sus posibilidades económicas. Además, el mencionado Don Francisco, se encargará en connivencia con un alto funciona- 
rio argentino, y a cambio de dinero, de obtener una carta de llamada falsa, obstáculo burocrático con el que se encontraban la entrevistada y su familia. Una vez en Cádiz, se hospedan en una filial del hotel Roma, sito en la calle Buenos Aires, a la espera de la partida que se produce dos dias después. La informante narra como muchos emigrantes solían ser retenidos en las pensiones durante bastante tiempo, a la espera de algún barco, con el objetivo de obtener de ellos el mayor beneficio posible. Algunos, esquilmados sus ahorros en las pensiones, no tenían más remedio que vivir en la calle mientras esperaban ser embarcados:

“... estaba éste (...) que era el que, el que tenía la confitería enfrente de nosotros, en la calle Catalanes, y cuando lo vimos alli ya hacía como un mes que se había ido de Motril... o más, más, y lo encontramos con un carro, tirando de él, llevando bultos, qué sé yo, porque no sabía qué hacer, porque ya no tenía nada, y no tenía dinero, estaba en la calle...".

El objetivo de la familia, una vez llegados a Argentina, era dirigirse a la ciudad de Rosario donde unos paisanos, establecidos allí un año antes, le habían conseguido una casa de alquiler. Con anterioridad a la estancia en Rosario, permanecieron hospedados durante dos dias en un hotel de la ciudad de Buenos Aires. La grandeza y carácter populoso de la capital, no provocaron precisamente una buena impresión a la entrevistada, el miedo hacia un futuro incierto, a lo desconocido y a la soledad, ganan la batalla a la curiosidad y a la búsqueda de nuevas experiencias:

“...la impresión es que cuando te vienes así, que te bajas del barco, y te ves completamente desamparada, y nada, es muy feo y muy triste por muy linda que sea la ciudad, feísimo, porque no ves ninguna cara conocida, nada, no ves nada, y sabiendo que no te espera nadie".

Una vez asentados en Rosario, el primer objetivo familiar fue la búsqueda de trabajo. La enfermedad de la madre, la incapacidad del padre para trabajar debido a su edad, y el escaso salario que recibía el hermano, obliga a la entrevistada a buscar empleo para contribuir al sustento familiar. Este acontecimiento provocó un cambio radical en su vida cotidiana. En su Motril natal nunca se vio impelida a trabajar gracias a la buena situación económica de la que disfrutó. La situación a la que ahora se enfrentaba difería en gran medida a la cómoda vida que llevó con anterioridad. La necesidad de formar parte del mundo laboral, y a la vez acometer las labores del hogar ayudando a su madre enferma, la convierten en una mujer más activa y dinámica, incluso se produce un cambio en su carácter tímido y retraído:

“... a mi me daba miedo de prender un fósforo, que te lo diga mi hermano, ... nunca, y bueno, aquí no hubo más remedio. Yo, ya lo sabe tu mamá, tu tía, como era yo, una poquita cosa, no me atrevía casi ni a hablar".

La informante se dedicó a la confección, gracias a los conocimientos que ya poséía. Su hermano explica, con notable orgullo durante la entrevista, los porme- 

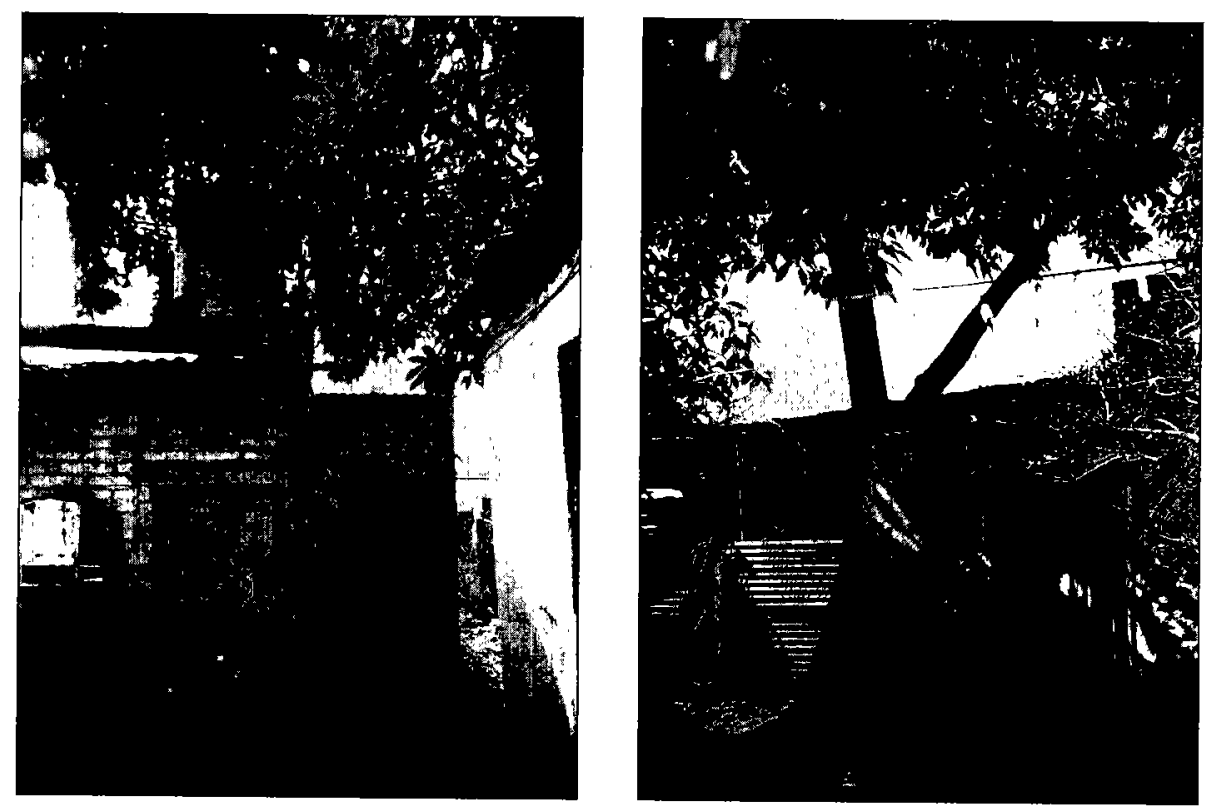

"Tipo de vivienda de autoconstrucción en un barrio periférico de San Miguel de Tucumán en donde viven algunos de nuestros informantes".

nores de su trabajo. Confeccionaba en su propia casa pantalones para un sastre, empleando como herramienta de trabajo, una máquina de coser manual heredada de su abuela, una de las pocas posesiones que no vendieron en Motril y que consiguieron llevar para Argentina. El jornal que recibía era de cinco pesos. Más adelante, se dedicará exclusivamente a la confección de cuellos de camisa, también para un sastre, debido a la mayor comodidad de este tipo de trabajo y al buen jornal que por él recibía: doce pesos por cuello.

La penuria económica en la que la familia llegó a encontrarse en Argentina, provocó en la informante una sensación de desclasamiento. Su mayor deseo era conseguir, con su trabajo y el de su hermano, el mismo status socio-económico que poseían en su pueblo natal:

"... yo tengo qué coser porque tenemos que salir de aquí, porque ésta no es la vida nuestra, y tenemos que volver a la nuestra, y hasta que mi hermano no compró el primer bar yo seguí cosiendo".

Nuestro personaje no sólo aparece como sustentador económico de la familia, actúa además como sustentador moral. Según su hermano, con su actitud infundía valor y ganas de seguir luchando en los momentos de angustia. La institución familiar resulta esencial para la entrevistada. Sus deseos de unidad incluso la llevan a considerar beneficiosa la estancia en Argentina, a pesar de las carencias sufridas porque gracias a ella su hermano, quien llevaba en Motril una vida "licenciosa", volvía al núcleo familiar: 
“... pero al volver aquí fue más, más unión para la familia, porque a mi hermano ya lo apartó del vicio, porque no podía y no tenía con quien".

"... lo único que salvó a mi hermano fue cortar de raíz, porque allí en

España, habiéndose cambiado de lugar o a otro sitio, no lo hubiera salvado".

La añoranza y el deseo de volver al lugar de origen, a pesar de más de cuarenta años de estancia en Argentina, es un elemento muy presente en algunos momentos de la entrevista:

"Me gustaría porque nunca se puede olvidar la tierra donde uno nació, porque las verdaderas raíces están allí, pero sé que si me voy, no me voy a olvidar de esto. Yo digo que el emigrante pierde parte de su identidad cuando sale de su patria. Yo no lo volvería a hacer".

Los lazos familiares con España prácticamente desaparecieron, en cambio poseen para la informante, un fuerte carácter sagrado, que demuestra definiendo a una de las encargadas de la entrevista, pariente lejano al que nunca había visto, de forma posesiva:

"Es, la, la, la primera vez después de cuarenta y un años que yo veo a alguien de los míos, y ite parece poco?...".

\section{Tercer Testimonio (Rosario, 29 de Julio de 1993)}

El informante es un varón de 73 años de edad originario de Motril (Granada). En 1952, emigra a Argentina junto con sus padres y su hermana. En el momento de la partida el cabeza de familia contaba con 60 años, la madre tenía 58 años, y su hermana 26 años, nuestro informador contaba con 30 años y era considerado como el jefe del grupo.

Una vez instalado en Argentina e iniciada su nueva vida, con todas las dificultades que ello conlleva, comienza a trabajar y se casa, no teniendo descendencia de este matrimonio. En la actualidad nuestro informador está divorciado.

La experiencia vital relatada por este granadino es especialmente interesante en lo que respecta a su tierra de origen, Motril, de la que nos hace una detallada descripción, introduciéndonos en el Motril de principios de siglo, coyuntura histórica que hizo de este pueblo un foco de emigración dentro del contexto andaluz de la época.

Así mismo, el informante, hace una diferenciación entre los dos procesos migratorios que se originarían, uno a principios de siglo, y el otro en la posguerra española, analizando las causas que provocaron uno y otro.

Igualmente es de particular interés la visión que nos da sobre la presencia de motrileños en el noroeste argentino, nos habla de una vía directa para llegar a esta región, pero también de una vía indirecta, cuando la emigración tenía como destino Brasil, pero que debido a las condiciones infrahumanas que este país les ofrecía, decidían, en muchos casos, una posterior emigración o huida hacia Argentina.

Por último, hace una reflexión acerca de su propia experiencia como emigrante, prolija de sentimientos y emociones, recordando cada instante vivido con intensidad. 
Este testimonio es rico en detalles y en información, lo cual es favorecido por el discurso denso y fluido que caracteriza a nuestro entrevistado. Del mencionado relato hemos decidido hacer una selección de aquellos aspectos más trascendentes, lo cual nos ha resultado una dificil tarea, debido a que todo él es una "historia de vida" nada desechable.

Por razones de metodología hemos decidido estructurar este testimonio en dos partes diferenciadas, tomando como línea divisoria el trágico hecho de la Guerra Civil española.

\section{-Motril desde principios de siglo hasta la Guerra Civil.}

La ciudad de Motril hay que enmarcarla dentro del contexto del agro andaluz de esta época. Sin embargo no hay que olvidar el carácter específico y diferenciador que le da el cultivo de la caña de azúcar; dicho cultivo constituía la base y el motor de la vida de la zona hasta los albores del siglo XX. Entrando a continuación en declive a causa de la introducción del azúcar de remolacha en el circuito mercantil.

Podemos decir, en definitiva, que Motril se desenvolvía en esta época en un ámbito esencialmente agrícola. Es fundamental, por tanto, conocer el régimen de tenencia de la tierra para comprender la problemática socioeconómica de la comarca. Nuestro informante nos da cuenta de ello:

"Aquí la propiedad no existió nunca más que para cuatro manos. Si entramos así en el conjunto de la vega de Motril, extendida hasta Salobreña,

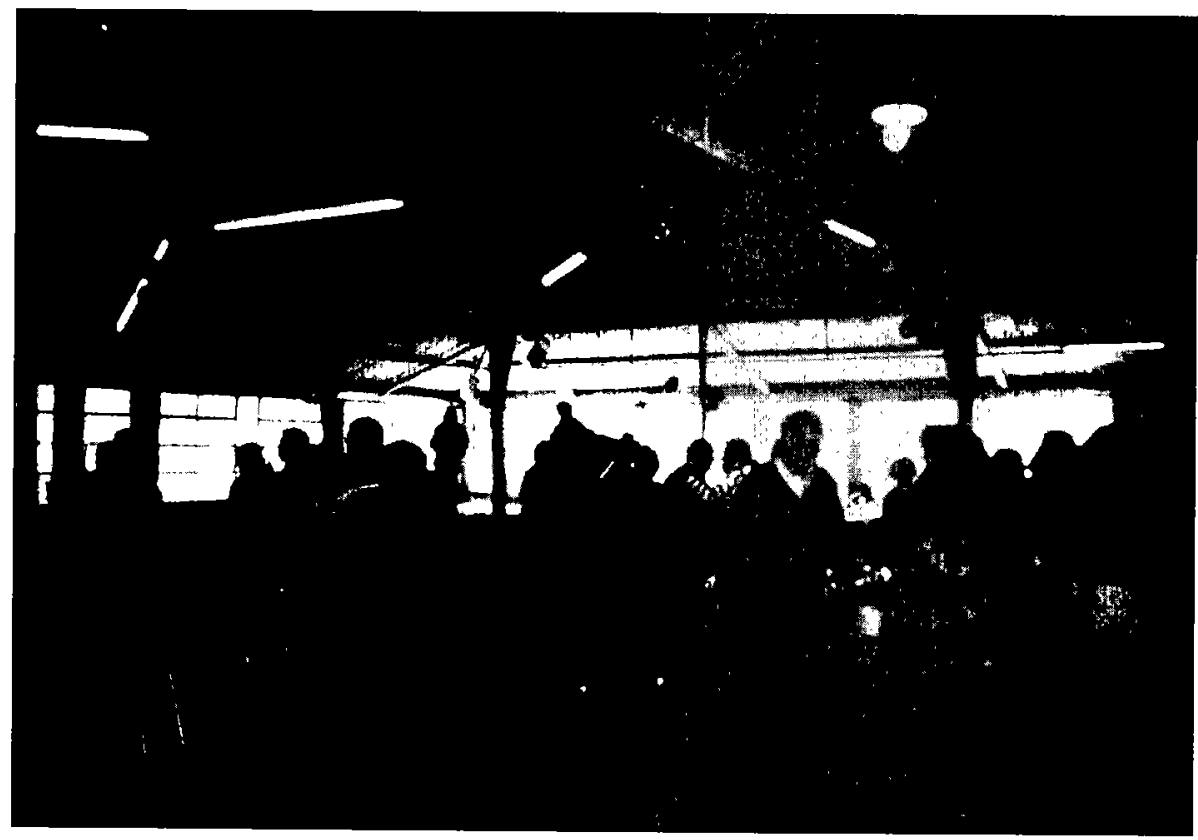

"Fiesta Dominical en un centro de emigrantes de la ciudad de Rosario". 
tenemos entendido que la vega era de la Condesa de Bornos, que tenía una administración particular aquí en Motril; estaba la administración de Burgos (1), que también tenía administración acá; y estaba el Conde de Agrela, que tenía administración.(...) Estos señores, después arrendaban la tierra a sus arrendatarios, la arrendaban y les pagaban una cuota establecida (...). Lo que se heredaba era que las tierras se podían subarrendar, porque iba pasando de unas manos a otras, pero siempre era propiedad rentable para el poseedor de la tierra, que por lo general en Motril, o vivía en Madrid, al mejor de los estilos andaluces, muy lejos del predio, y el predio para que los exploten los otros".

Efectivamente, Motril, en este sentido participa de las características del agro andaluz, donde existe una aristocracia, que detentaba la propiedad de la tierra, frente al conjunto de la población desposeída, sin tierras, y sin apenas instrumentos de trabajo, que dependían directamente de la mencionada aristocracia. Motril se halla dentro de un subconjunto que forman las hoyas mediterráneas, que por sus características geofísicas, es una zona diferenciada dentro del medio agrícola andaluz:

"(...) Las hoyas mediterráneas, por la calidad de sus tierras, y por la diversificación de sus frutos, no se pueden tener en cuenta como latifundios (...) hay que tomarlo por otro factor, el factor de rentabilidad de la tierra (...). Con veinte marjales de tierra (veinte marjales equivalen aproximadamente a cinco hectáreas) de cultivo rotativo, en donde las tierras de Motril, de esta hoya mediterránea, se dan cuatro frutos al año. Entonces, se da el caso de que con veinte marjales, y aún con menos vivía una casa de familia (...) con seis hijos y el matrimonio ocho, ocho bocas para comer".

Sin embargo, como ya se ha dicho con anterioridad, la mayor parte de la tierra, el 80 o el 90 por ciento estaba en manos de unos cuantos hacendados, dejando tan solo alrededor de un 10 por ciento de la tierra para pequeños propietarios poseedores de 20 o 30 marjales.

Con relación a esta situación, nos relata un suceso de vital importancia que desencadena uno de los primeros ciclos migratorios hacia el nuevo mundo en los albores del presente siglo. Este es el incendio de la fábrica que los Marqueses de Larios poseían en la localidad. Parece ser que el motivo de este siniestro es la arbitrariedad del Marqués de Larios en la gestión de su fábrica, lo que provoca esta respuesta "revolucionaria" del pueblo motrileño. Nuestro informante nos hace una detallada síntesis de estos acontecimientos:

"Eso fue en el año 1902 o el 1903 (2). Principios de siglo. Allí en el pueblo todos estaban comprometidos. Llegaron a tener tal compromiso hasta que fueron a llegar a la Casa Cuartel de la Guardia Civil, obligarles a salir, a toda la Guardia Civil, que eran 15 ó 16 números, vestidos de uniformes y

(1) Perteneciente a la familia de los Burgos, descendiente de Francisco Javier de Burgos, Ministro de Fomento con Fernando VII, que hizo la repartición en provincias de España.

(2) Al final del artículo se muestra una imagen de estos sucesos acontecidos en 1911. 


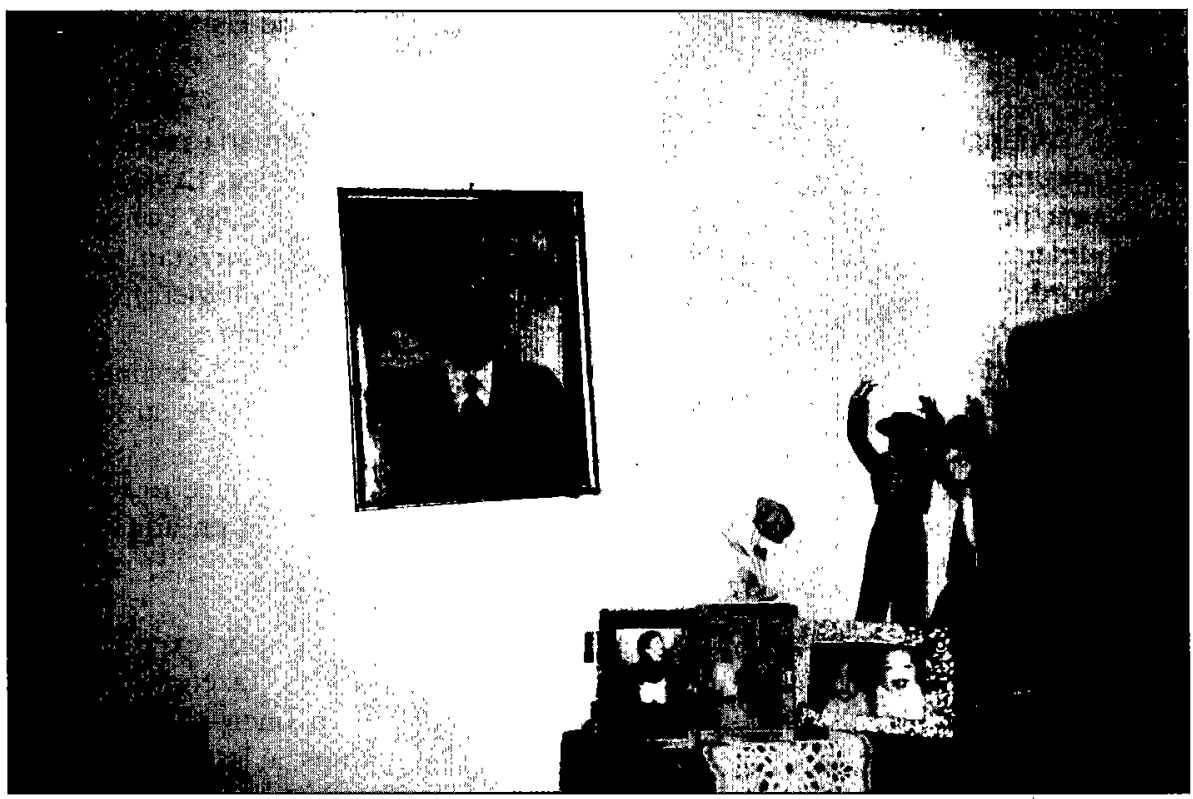

"Altar" de un emigrante: recuerdos de España, el pasado y el futuro".

con armas largas, encabezando la manifestación, y el pueblo apuntándoles para que estos señores no hicieran uso de sus atribuciones de represión. El alcalde de Motril, que en un principio se puso al frente de la manifestación, que se Ilamaba Don Luis Vinuesa, aprovechando un descuido de los manifestantes (...) se escapó vestido con ropas de mujer".

Continúa explicándonos las causas del suceso:

"(..) No fue una rebeldía sin causa, sino fue una rebeldía con causa justificada, para sublevar las conciencias, los espíritus, y la enervación de la fuerza que lleva a la explosión del hombre. Se quemó esta fábrica porque el "señor" Marqués de Larios (...) estableció así: "Yo pago cuando quiero, pago lo que quiero, y hago lo que quiero, y pago el precio que quiero" (...). Ellos ponían los precios, las básculas no eran controladas, lo puedo decir tranquilamente, las básculas robaban, eran las básculas del demonio, robaban siempre al productor en beneficio siempre del contratista".

Finalmente, las consecuencias que se generan de este acontecimiento eran las de esperar conociendo el ambiente represivo dominante:

"A partir de la quema de la fábrica del Marqués de Larios (...), entonces hubo un éxodo masivo de gente de Motril que partieron hacia América, pero 
todos escapando del garrote vil o de las grandes palizas de las fuerzas represivas".

El contingente humano que partió en estos momentos formaría parte del primer ciclo migratorio de principios de siglo con destino a América. Existieron dos vías, una primera con rumbo a Brasil, que después, debido a las condiciones infrahumanas a las que fueron sometidos, huyen a Argentina, concretamente a la zona nordoccidental, y la segunda vía, serían aquellos que se dirigieron directamente al noroeste argentino.

La elección de Brasil y el noroeste argentino como punto de destino venía determinado por la similitud de los productos cultivados con los de su zona de procedencia (caña de azúcar).

Con respecto a este ciclo migratorio la descripción que nos hace es realmente elocuente, acerca de las calamidades y penurias que sufrieron en aquellas tierras lejanas:

"Pero Brasil, en aquellos tiempos, tengo entendido, por experiencia y por relatos vividos, fueron muy terribles. Alli en aquellas "fazendas" brasileñas nunca se terminaba de pagar (las deudas), era tan oneroso y tan poco válida la vida de un hombre, que si nos remontamos a la esclavitud del negro, no hay gran distancia entre la esclavitud del negro y la esclavitud del blanco. Nunca pagaban, entonces salían huyendo, muchos quedaron en el intento, tendidos con los ojos mirando hacia arriba (...) bajo la persecución del rifle, de la persecución implacable de los "coroneles" (3) de las "fazendas", y llegaron a Argentina ..."

A continuación el informante nos narra como la ilusión y el ansia de libertad de estos motrileños se transforma en decepción y desesperanza, al encontrarse en una situación similar, cuando no peor, que la que habían dejado en la madre patria:

"Esta gente llegaron a la Argentina queriendo encontrar una provisión de libertad añorada por tantos, y por escapar de una muerte cierta, porque el latifundista brasileño no empleaba nada más que el rifle como respuesta a la palabra. Al llegar a Argentina no cambiaron en mucho la situación de estos emigrantes (...). Se establecieron buscando las zonas azucareras de la caña de azúcar, San Miguel de Tucumán, Santiago del Estero, Mendoza, San Juan..."

Muchos de estos motrileños fueron a parar al Ingenio Ledesma, situado en la provincia de Jujuy (Argentina), en el que se vieron de nuevo envueltos en la trama de deudas imaginarias que se les adjudicaba, del que era difícil salir, pues nunca se terminaba de pagar. A este ingenio llegó un tío suyo como cabeza del grupo de motrileños que ingresaron en él, el cual ayudó a escapar a unos primos segundos suyos, y él mismo decidió huir debido a las insoportables condiciones

(3) "Coronel, en el lenguaje popular, sujeto de mucho dinero, dado a la buena vida, generalmente gran propietario, etc., patrón, persona adinerada, en relación a los empleados a los que paga". (Cita de Jorge Amado). 
de vida. En la actualidad esta precaria situación la viven los indios bolivianos, recluidos a modo de "reserva".

Hasta ahora hemos tratado las distintas causas de emigración del agro motrileño en las primeras décadas del siglo XX, a continuación, haremos referencia a las circunstancias generadas por la Guerra Civil, que provocaría una segunda oleada migratoria.

\section{-Motril después de la Guerra Civil.}

El 18 de Julio de 1936 estalla la guerra. Todo iba a cambiar en el pueblo. Muchos han de huir, abandonándolo todo, sus cosas, sus tierras, por no hablar de otros aspectos no materiales de la vida humana.

Situación que fue aprovechada, como desgraciadamente suele ocurrir en las tragedias, en este caso por los "postores", nombre por el que se conocen a los capataces en esta zona, para enriquecerse a costa de los que habían huido. Estos "postores" o capataces eran el eslabón que unía a los grandes hacendados con los pequeños productores. Su función, básicamente, era la contratación de mano de obra para la corta de la caña de azúcar. Estos "postores", con métodos muy cuestionables, llegan a ser poseedores del usufructo, y de la comercialización de los productos de la tierra, concentrando gran cantidad de tierras a su nombre. Así nos habla de ello nuestro informante:

"Cuando viene la Guerra Civil española, y vienen el éxodo y la ignominia que tuvieron que sufrir familias enteras, hubo ciertos señores en Motril como (...) que llegaron a tener 700,900 y 1.000 marjales. Y, ¿qué pasó con esto?, no solamente el dolor de la apropiación de la tierra indebida, de aquellos que huyeron escapando a una muerte, que por lo menos para ellos lo veían así; (...) hicieron la liquidación a su nombre, de aquellos que salían huyendo, y estas tierras, esos rendimientos de la tierra fueron liquidados sin preguntar a quien (...)".

Nuestro informante tenía 17 años cuando terminó la contienda bélica, vivió de cerca la posguerra, la miseria, las enfermedades y el hambre que se extendia por los pueblos de aquella España en ruinas. El vio como su mundo y el de su familia se veían terriblemente alterados a consecuencia del enfrentamiento civil; la posición económica que su padre había conseguido con su estancia en 'Cuba, años atrás, se derrumbaba mientras veía la miseria en la que se hundía su pueblo:

"A partir del año 39, empezó la verdadera tragedia de la posguerra en Motril, la gente que venía en éxodo obligado, el retorno a sus hogares, hogares que fueron destruidos, la tierra incautada (...). Entonces, como consecuencia de aquello se da la triste década de los años cuarenta, (...). Hay que hablar de un sistema que iba en contra de la vida humana, (...) hay que hablar de exterminio, hay que hablar de genocidio; entonces, como consecuencia de aquello pues el que pudo poner agua de por medio, pues era bien aventurado".

Con estas palabras sintetiza este granadino la terrible situación del Motril de los años cuarenta, donde el sueldo de un obrero de la construcción o del campo apenas si llegaba para comprar pan. 
A esta situación de decadencia en todos los sentidos, económico, social, cultural, humano, etc. hay que añadir el ambiente de miedo, represión, y control del recién inaugurado régimen franquista.

En la región granadina, al igual que en otras zonas de España, la geografía abrupta dio cobijo al fenómeno guerrillero (maquis) en los años de la posguerra. Teniendo como correspondencia el apoyo que hombres y mujeres ofrecieron para sustentar a los grupos guerrilleros con la logística necesaria en su lucha contra el régimen.

El entrevistado nos cita el caso concreto de una familia motrileña, que según dice, tan solo proporcionaba alimentos a la guerrilla, al ser descubiertos han de huir hacia América, desde donde son reclamados por parientes. El padre del entrevistado les prestó cuatro mil pesetas para los pasajes. Así, cuando en 1952, nuestro informante y su familia emigran a Argentina, contarán con el apoyo y la gratitud de aquellos a quien anteriormente habían ayudado a escapar de una muerte segura. El relato que nuestro informante nos proporciona es el siguiente:

“(..) Además había una familia motrileña (...) que para escapar de una muerte cierta vino el momento adecuado de un pariente que lo reclamaba en una carta de llamada real. Eran gentes muy buenas, que tuvieron combinación con la gente de la sierra, porque no tenían más remedio que llevarles alimentos, o estabas con la Guardia Civil, o estabas con "ellos".

Este es el panorama desolador en el que se desarrolla el segundo ciclo migratorio corriendo los años cuarenta y cincuenta. El informante habla con gran dolor de su experiencia personal al tener que abandonar su patria, su tierra, sus raices y sus recuerdos, quedándole una honda tristeza por el mal trato que su tierra le ofrecía en aquella triste realidad, sentimiento compartido por todos los emigrantes:

"(...) Porque parece que la gente sobrábamos en nuestra tierra. Parece que nuestra tierra fue como una "madraza" que mal nos parió, porque ya teníamos que ser parias del destino. Nuestro destino fue el encontrar lo que habíamos perdido durante la guerra del 36, una buena posición con dinero amasado en Cuba por mi padre, posición que se vino abajo por la honradez que demostró mi padre en el año 39, cuando no quiso incursionar en el mercado negro (...)".

En consecuencia, su familia decide marchar a América en busca de la oportunidad que España les negaba, con el fin de recuperar la posición económica que habían perdido.

A continuación nuestro entrevistado nos narra las circunstancias que rodearon su embarque y las vicisitudes de su posterior viaje hacia América, dándonos detalles de toda esta infraestructura.

Su primer contacto con esta realidad es a través de la figura del "gancho", un tal Don Francisco, que con residencia en Cádiz, y como representante de un sistema mafioso, se dedicaba a reclutar personas en los depauperados pueblos de Andalucía para embarcarlos hacia América, embaucándolos en múltiples engaños y abusos. Con estas palabras lo describe: 
"Entonces pasaba un tristemente célebre personaje que fue Don Francisco, pasaba por las calles de Motril, y claro, lo adoraban como a un apóstol, porque aquel hombre vendía pasajes. Era un sevillano, que fue un testaferro de iotros, que estaban a su vez conectados con los consulados americanos y con las autoridades argentinas, y en contubernio indecoroso por ambas partes que se "fructuaba" las famosas cartas de emigración donde aparecía un reclamante en Argentina, que no existía, y un señor que pagaba por esta carta de llamada. Así se legalizaba lo que era ilegal. Era un comercio de trata de blancos".

Después de realizar la venta de sus posesiones en Motril y demás trámites burocráticos, marchan a Cádiz donde permanecerán cuatro días instalados en un hotel de lujo, filial del hotel Roma, hasta el momento del embarque.

Las palabras de nuestro informante con respecto a los dias inmediatamente anteriores a la partida están llenas de tristeza, resentimiento y resignación, ante la visión apocalíptica que tenía del futuro de su familia y de sí mismo:

"En un hotel de lujo en la calle Buenos Aires, (...) que no nos daba comida, pero que tenía un albergue muy decente (...) aquel hotel donde fuimos nosotros solos, porque aún teníamos dinero y conservábamos un elitismo que no tenía fundamento de base alguna".

... Con respecto al viaje:

"Ya para mi aquello fue tétrico, y cuando vi que el anterior día a nuestro embarque estaba atracado aquel ataúd blanco que era el "Cabo de Hornos", se me acabaron hasta las ganas de vivir, y yo que iba al frente de un grupo por tener treinta años, y mi padre sesenta, y yo era el más inútil de los, cuatro, porque yo no sabía nada, de nada, de nada. Entonces, claro, cuando yo me metí en aquel barco, cuyos pasajes solamente costaron 72.000 pts., porque fuimos obligados a viajar en camarotes de cuatro plazas, como turistas elegantes, cuando yo tenía que haber ido en la panza del barco como iban todos aquellos desgraciados (...), allí estaba subyacente todo un mundo, había 1.000, 2.000 personas, e iban en busca de un horizonte perdido.

Y ya a través del océano empezó la tragedia. (...) Con escala en Dakar, donde yo vi hacinado a la miseria humana del negro, tirados en la calle, arrojados frente a los grandes negocios franceses (...). Allí fue donde me di cuenta del destino que a mi me esperaba. Que cuando llegué a América no fue así como yo lo vi en Dakar, pero fue algo parecido".

Finalmente, tras diecisiete dias de viaje, llegan a Buenos Aires, donde se instalan en un hotel, en el que permanecerán cuatro días, a la espera de que llegasen a recogerles el único contacto que conocían en aquellas tierras extrañas: la familia a la que antaño su padre había ayudado a huir de la persecución franquista. Esta familia, como agradecimiento, les brinda su apoyo, y los ayudan a trasladarse a la ciudad de Rosario, donde serán alojados en casa de unos primos suyos. Al cabo de dos meses se alojarán en una vivienda de alquiler propio. 
El informante nos describe como fueron estos difíciles momentos de empezar una nueva vida. Su padre empezó a trabajar, pero debido a su avanzada edad, los sindicatos no lo admitían, por lo tanto recayó sobre nuestro informador la responsabilidad ineludible de mantener a la familia. En un principio, simultaneaba su trabajo como obrero en una fábrica de "fideos" Minetti, con la elaboración de coñac, empleando para esto, una técnica aprendida en su pueblo natal, dándole en poco tiempo al licor un envejecimiento similar al de dos o tres años, siendo por esto este producto fácilmente vendible, permitiéndole salir adelante. Pero, por consideración a su padre, abandona este negocio que no estaba bien visto.

Hay que destacar de este testimonio la valoración que el entrevistado hace del trabajo de su hermana:

"Porque al fin y al cabo cuando llegamos aquí, a América, la única que nos hizo salir de la miseria fue mi hermana, que en quince días aprendió a coser el pantalón".

Nuestro entrevistado, con un verbo fluido y elocuente, nos ha ido dando pinceladas de su existencia, que en cierto modo es similar a la de cualquier otro emigrante que en circunstancias parecidas ha de tomar la determinación de buscar nuevos horizontes en tierras lejanas y desconocidas. Esta experiencia migratoria, supuso para nuestro entrevistado la posibilidad de un doble viaje, uno físico, que supuso el alejamiento de sus horizontes conocidos, y otro iniciático. Este viaje interior, le reportaría una evolución en su personalidad, desde el momento mismo en que sube las escalerillas del barco, puesto que comenzará a conocer otra realidad distinta a la suya cotidiana, dado que él es representante de la burguesía motrileña, y exponente de una actitud ácrata ante la vida, educado sin ningún tipo de responsabilidades.

Desde su primera incursión en el mundo laboral (fábrica de pasta, Minetti), ya en tierras argentinas, y en contacto directo con la realidad socioeconómica, irá creciendo en él una actitud sindicalista, de enfrentamiento directo con las autoridades sindicales peronistas (4). Todo ello generará un cambio en su personalidad, imprimiéndole nuevos principios.

A estas altura de su vida, cuando rememora todas las vicisitudes pasadas, lo hace con un sentimiento de melancolía y tristeza, no exento de decepción, pues hoy, con setenta y tres años, al volver la vista hacia atrás, parece sentir que el fruto obtenido no se corresponde con el esfuerzo empleado, siente, quizás, que no mereció la pena dejar España. Hoy desea volver pero se encuentra con que aque1la España que en 1952 "lo empujó a otras tierras", hoy en 1995, decidido a volver se encuentra con trabas burocráticas y económicas por parte de la administración.

Para concluir, hemos escogido una frase de este emigrante motrileño, cargada de sentimientos, y que sintetiza lo que para el significa la emigración:

"La vida del emigrante es un desgarro total, (...) un desgarro brutal de la carne".

(4) Se refiere a la C.G.T. (Confederación General de Trabajadores) de Argentina. Fue el sindicato vertical argentino de inspiración "peronista", uno de los pilares fundamentales del mencionado régimen. 


\section{Cuarto Testimonio (Tucumán, 20 de julio de 1993)}

La informante fue entrevistada en Tucumán en 1993 por dos miembros del grupo. Es una señora de 74 años de edad, viuda ya, que emigró a Argentina, en 1952. Salieron del puerto de Cádiz después de tres largos meses de espera alojados en una pensión de traficantes de las contrariedades y los sueños humanos: las mafias de la emigración.

Zarparon en la época en que una coyuntura histórica arrastró a su familia al viaje sin retorno:

"Así que yo me vine a la Argentina y todo para mi como si hubiera muerto. Ya no volví a verlos más. He llorado, hemos llorado todos, pero no podíamos hacer nada, no teníamos para irnos otra vez".

Un elevado número de andaluces partieron poco a poco dejando para siempre su tierra natal. Los factores coyunturales son: la miseria de la posguerra en la España franquista, y la propaganda populista y poblacionista de Perón.

El tipo de emigración que realiza nuestra informante con su familia se encuadra perfectamente entre las efectuadas por motivos económicos. Su marido, con espíritu de agricultor y sueños de terrateniente, los conducirá hacia la "Conquista del Nuevo Mundo", buscando la tierra prometida por Eva Perón, en la que más tarde no encontrarán leche y miel, ni siquiera la tierra:

"... entonces, mi marido: "yo le voy a escribir a la Eva (Perón), porque ha estado en España y dice que a todo el que quiera tierras se las vamos a dar" -digo- "ipero tú estás loco, la presidenta te va a contestar, ni te va a contestar!. "Que sí, que le voy a escribir"; "ah, de todas maneras escribe"; y la carta, esa carta la mandaron al barco, y dijeron que sí, que ya teníamos las tierras, y las tenían para dárselas... pero luego, al morir la presidenta, la Eva Perón ya se terminó todo y llegamos a la Argentina sin un peso, sin una peseta".

Su 'marido, buscando "El Dorado" y nublados los ojos con la visión de un futuro prometedor, viéndose propietario de una hacienda argentina en una fértil tierra conferida por Eva Perón, desembocará en el mafioso mundo de la emigración ilegal, controlado desde Cádiz, plataforma de emigración, por los "ganchos", que realizaban toda una campaña propagandística por los pueblos andaluces, presumiendo de las mejoras económicas de otros más audaces que salieron para América Latina gracias a sus mediaciones.

Nuestro informante coincide con otros entrevistados al describir al "gancho" que les "facilitó" la partida, un tal Don Francisco, que visitaba los pueblos contratando el viaje a lo soñado:

"Si, de éste. No lo conocía de nada más, porque llegó a Motril y mi marido habló con él y le dijo que sí que era verdad, que tenía que dar la plata adelantada. Entonces nosotros agarramos y juntamos la plata que habíamos juntado toda y se la metimos en el bolsillo al hombre éste, sin que él la contara ni nada. Le dimos 10.000 pts. a cuenta, y dijo que él lo iba a llamar". 
Pero no llama y el emigrante que ya "casi está arando sus tierras" se impacienta, ansiedad con la que juega el "gancho", pues la familia decide partir hacia Cádiz donde se alojarán en una pensión, propiedad también de Don Francisco, durante tres meses, aguardando el barco de las Américas, en pésimas condiciones y que les reporta un aumento de beneficios al tal Don Francisco, pues tendrán que desembolsarle 5.000 pts. más por los gastos de estancia en su pensión. Así, cuando llegan a Argentina "no teníamos ni una peseta, el "gancho" iba y se llevaba la plata de todos; era el patrón de la pensión".

Para pagar los gastos (15.000 pts. en total), su marido había vendido el "pedacito" de tierra que tenían en Motril por la Rambla de las Brujas, porque para emigrar había que poseer, al menos, algo que vender, un trocito de tierra, un minifundio, característico de la estructura de propiedad de la tierra en Andalucía Oriental:

" Mi marido vendió todo lo que teníamos... Los dos pedacitos de tierra los vendió".

El viaje fue toda una pesadilla: su hijo pequeño (de 1 año) enfermó durmiendo en las bodegas con un fuerte olor a pintura y humedad y, lo mas importante, no quería emigrar (5), solo seguía la decisión de su marido, el cual, sí disfruta de su viaje pese a las malas condiciones:

"Perdida, yo estaba perdida... Y veía la comida y me daba asco... y había bailes, y mi marido decía: "Baila hija...". Y yo: "A mi me dejas tranquila que yo me acueste". Luego tenía al Miguel casi medio muerto, con unas fiebres que volaba".

El ejemplo de su marido coincide con la visión que de los emigrantes nos ofrecía un cocinero de barcos de pasajeros al que también entrevistamos: "El emigrante no iba mal en el barco; ninguna mala condición le era adversa pues iba cargado de ilusión".

La llegada a Buenos Aires es la llegada al descontento: sin dinero, sin tierras y con toda una familia. No saben que hacer, y con el dinero prestado de un paisano que venía con ellos en el barco viajan hasta Tucumán, donde ella tenía lazos familiares: una tía que ya pertenecía a una generación anterior de emigrantes. De aquí la idea de viajar a Argentina: El camino estaba abierto.

Una vez allí, mi marido, sin tierras, deberá realizar los más variados oficios: estucador, medianero en una hacienda (con derecho a trabajo y medio usufructo), obrero en una fábrica de herramientas, etc. Alquilarán una pequeña habitación para vivir, propiedad de la tía, y de a poco construirán una pequeña y casi desvencijada "piezita" donde montarán una verdulería que conservan en la actualidad, y que no suele reunir los requisitos necesarios de higiene, por lo que continuamente se veían obligados a cerrar. Hoy subarrendada a unos nietos de emigrantes originarios de Málaga.

(5) Ella emigra involuntariamente por presiones de los elementos femeninos de su familia, madre y abuela, fieles exponentes de un matriarcado rural, que la obliga a emigrar con su marido con el objeto de mantener la unidad familiar y evitar una carga económica añadida. 
A los setenta años de edad, mientras nos narra el fracaso de la aventura, la entrevistada recuerda, idealizada, su juventud en la tierra natal, la familia y la vecindad:

"En mi casa éramos cuatro hermanas y un hermano, por cierto, todos muy felices; mi padre muy bueno, mi madre también. Vivíamos muy bien, pobres pero sin problemas; no debíamos a nadie ni pedíamos a nadie nada prestado".

A pesar del testimonio, en ningún momento muestra deseos de volver, su vida y descendencia están ahora en Argentina. Se despidió para siempre.

A través de la grabación nos llega la voz, casi quebrada, de nuestra informante; su emoción, al evocar su "historia de vida", nos habla del desgarro y el dolor del emigrante. Con su voz, la historia oral, puede hacer que comprendamos mucho mejor el fenómeno que estudiamos; su voz, que no aparece en los documentos. Así, en su testimonio, encontramos la hiperbólica despedida, para siempre de su familia.

"iAy!, muy mal, bastante. Ya te digo yo, cuando yo llego a mi casa para despedirme, por la calle La Esparraguera, sentía los gritos de mi madre. Y llegamos alli, mi padre justo había salido de la pieza, estaba poniéndose el botón del chaleco, estaba así llorando, era todo un drama. Yo no me quiero acordar, porque, ¿para qué?..."

\section{PROBLEMATICA SOCIO-JURIDICA DEL RETORNO}

En nuestro viaje y trabajo de campo, tuvimos la oportunidad de constatar: el deseo de algunos españoles de la tercera edad de retornar a sus lugares de origen, ya que la vida material se hace insostenible en el referido país. Como sabemos, la política económica neoliberal (made in Chicago) de Carlos Menen está sacrificando y empobreciendo, cada vez más, a las clases medias y populares argentinas, hecho del que no se hacen eco prestigiosas revistas de "macroeconomía" que alaban la "estabilidad" del peso argentino en la actualidad, en contraposición a la época de Raúl Alfonsín. Pues bien, dejemos la "macroeconomía" para los expertos, y vayamos a la vida cotidiana, a la cesta de la compra, más encarecida que en España, y con pensiones de jubilación de 15.000 pts. mensuales y sueldos medios de personal cualificado de 30.000 pts.

Algunos de nuestros informantes, sin vínculos familiares alli, quieren regresar; pero con la exigua pensión de 15.000 pts. y sin vivienda es imposible vivir en España. Desean, por tanto, acogerse a la pensión no contributiva; pero las leyes establecen un mínimo de dos años de residencia en España (a los propios españoles), residencia en calidad de "mendigos", se supone, para poder acceder al cobro de la no contributiva. Las autoridades españolas resuelven el problema diciendo que "velarán por el retorno de sus emigrantes", que "regresen los que quieran para ser acogidos en un asilo, no necesariamente en el pueblo de origen, sino en el lugar que la administración disponga".

Esta misma problemática acerca de la dificultad del retorno aparece reflejada en la protesta de un emigrante español, residente en Rosario (República Argentina), presentada al periódico "El País" en la sección de "Cartas al Director", el pasado 4 de mayo de 1992 : 


\section{El emigrante español en América}

El artículo de nuestra Constitución Nacional dice así:

"El Estado velará especialmente por la salvaguardia de los derechos económicos y sociales de los trabajadores españoles en el extranjero, y orientará su política hacia el retorno". Y bien, este contenido no se cumple. El emigrante que ha alcanzado la tercera edad y que se encuentra en esta desolada América está dejado, por así decirlo, de la mano de Dios y del Estado, ya que muchos de ellos, entre los cuales me incluyo, estamos soportando el rigor más crudo de esta realidad social sin que por el momento tengamos una solución humana y solidaria. Pues, ¿cómo podemos hablar de una asistencia social con una asignación de 400, 500 ó 600 dólares al año? ¿cómo podemos retornar a España si por decreto se establece un mínimo de dos años de residencia en nuestro país para tener derecho a percibir la pensión no contributiva? ¿con qué comemos y cuidamos nuestra salud ya resentida por los años?.

Atengámonos, pues, al decoro internacional haciendo una justicia social que nos equipare a países que, como Italia, Francia o Suiza, atienden con la dignidad debida a sus ciudadanos en el extranjero. 